\title{
Measures against the abandonment of common property summer pastures: experimental evidence from joint appropriation-provision games
}

\author{
Ivo Baur $^{1}$ and Heinrich H. Nax ${ }^{2,3}$
}

\begin{abstract}
Common property summer pastures constitute longstanding evidence that the tragedy of the commons can be prevented through self-organization. As a byproduct of their sustainable governance, high nature value farming systems with well-integrated patchy landscapes have existed for centuries. These common pool resources-which have historically needed protection from overexploitation - today suffer from underutilization, and their continued use is often contingent on government subsidies. The current study sought to identify which user, institutional, and resource attributes contribute to the sustainable use of high nature value summer pastures. Taking as our point of departure a recent field study of Swiss Alpine grazing lands, we set out to experimentally identify the most promising mechanisms for successful resource management in this context. To do so, we implement a controlled experiment that closely mirrors our field observations ("field-in-the-lab"), and parametrize our experiment to replicate field data. Our focus is on the institutional linkage of provision and appropriation. Our treatments varied across a range of parameters, ceteris paribus, to isolate which governance elements are most relevant; we did so to identify which policy options and scenarios should be prioritized in practical policy evaluations. It turns out that underappropriation appears to be the main management challenge for Swiss common property pastures today. Our analytical results suggest that current governance institutions - and, more specifically, how they link appropriation to provision requirements - might need to be overhauled. The most promising avenues for doing so appear to be increased provision requirements, incentivized overprovision, and appropriation subsidies. Thus, our study highlights promising institutional adaptations at various governance levels that potentially counteract the decreasing use of high nature value common property pastures in Switzerland and elsewhere in Europe.
\end{abstract}

Key Words: appropriation; common pool resource management; field data; lab experiments; policy, provision; sustainability

\section{INTRODUCTION}

High nature value farming systems (HNVFS) are low-intensity grazing or crop production systems that are generally of marginal economic and high ecological value. They are the result of sustained integrated farming practices aligned with local soils, topography, and other environmental conditions and have created patchy and diverse agricultural landscapes that are rich in biodiversity and other ecosystem services. Many HNVFS are extensively used natural and seminatural grasslands in mountainous areas that are frequently managed as common property (Keenleyside et al. 2014, O'Rourke et al. 2016). Given their relatively low agronomic value and the state of today's farming technologies, these kinds of marginal and step-grazing lands are among the agricultural landscapes most prone to abandonment in Europe (Verburg et al. 2010, Plieninger and Bieling 2013). Given the widespread ecological and cultural appreciation of many HNVFS, their support has been a key mission of agricultural policies across Europe. However, despite the provision of substantial targeted subsidies, summer pasture abandonment and subsequent afforestation of formerly cultivated landscapes are frequently observed (Keenleyside et al. 2010). Although there is mixed evidence concerning the ecological consequences of farm abandonment in Europe in general (Verburg and Overmars 2009), in the case of Alpine summer pastures, there is consensus among scientists that land abandonment diminishes the ecological and cultural value assigned to Alpine agricultural landscapes (MacDonald et al. 2000).

The current abandonment and underuse of many Alpine grazing commons, as well as the need to subsidize their use, initially appears to contrast sharply with Hardin's predictions of the tragedy of the commons (Hardin 1968). In fact, many European cases are in the early stages of what might become an inverted tragedy of the commons, whereby high-value landscapes are grazed and maintained below (not above) the optimal levels needed to maintain habitat quality and biodiversity. In light of decreasing resource use today, these circumstances raise several questions concerning the suitability of some of the most famous cases of locally devised institutions - many of which were originally designed to mitigate overuse, and successfully did so. The literature on common pool resource (CPR) management in the real world is a mixed tale of both success and failure in terms of sustaining collective resources (Burt 1964, Ostrom 1990, Baland and Platteau 1996, Dietz et al. 2003). In organizing these mixed results, one finds that both experimental and empirical studies have greatly contributed to improving our understanding of how and which institutional traits matter. In that literature, failure is generally associated with resource depletion and pollution, and not with its gradual abandonment, as is the case with Swiss summer pastures. There appears to be a lack of empirical work investigating the vectors that drive land use decisions that, in turn, result in the gradual abandonment of common property land. The current study looks to address this research lacuna.

Our aim was to experimentally identify the determinants and candidate policies most promising in restoring optimal use and maintenance levels among HNV common property pastures; we were motivated by our previous work on the summer pastures of Grindelwald, in the Swiss canton of Bern (Baur et al. 2014, Baur and Nax 2018). In so doing, we delved deeply into the current state of affairs, in what has become one of the first (and perhaps best-known) success stories in the CPR literature (Netting 1976, 1981). We viewed our move from field data to a controlled laboratory experiment as a first step toward an experimental 
"field-in-the-lab" framework. The key innovation inherent in our framework was our modeling of appropriation and provision decisions as being institutionally linked, and where both affect the state of the resource. We did so because farmers in our field case and in many other use cases in Switzerland (Stevenson 2005, Landolt and Haller 2015) and neighboring countries (Casari 2007, Penker 2009, van Gils et al. 2014) face institutions that require them to conduct communal work (i.e., provision) in proportion to the number of livestock sent for grazing (i.e., appropriation). Accordingly, appropriation levels are first determined, given the allocation of rights of use. Second, depending on individual and collective appropriation levels, some local institutions assign provision duties as a function of individual and collective appropriation decisions.

Congruence between appropriation and provision rules has long been identified as a key feature of successful local governance institutions (Cox et al. 2010). In fact, we argued that the current institutional setting is designed to abate appropriation (via linkage with provision duties) and thus deserves a critical reflection in light of decreasing trends. Experimental data in hand, we investigated how appropriation and provision behaviors correlate, and how relevant comparative statics that we experimentally adjusted — such as changes in endowment, group size, institutions, and resource attributes - can affect appropriation and provision decisions. Finally, we compared the outcomes with optimal appropriation and provision levels, and identified which experimental variations, now interpreted as candidates for policy tools, are most sustainable. Doing so allowed us to identify promising institutional configurations that could potentially counteract abandonment trends among Alpine grazing commons. Our results can inform future policy investigations and randomized control trials (RCTs) as to which of the many policy options should be tested first.

This paper is structured as follows. The second section reviews related experimental work on coupled appropriation-provision behavior, and the third section describes the experimental design, notably how the field case translates into an experimental setup, and how the experiment was conducted. The fourth section presents the experimental results while focusing on treatment effects and the determinants of individual-level behavior. Finally, we discuss the policy implication of our experimental results with regard to the governance of HNV common property pastures in Switzerland; these results naturally have implications for the stewardship of other CPR systems governed by the institutional linkage of appropriation and provision.

\section{RELATED EXPERIMENTAL WORK}

We restrict our discussion of related scholarly work to experimental and formal contributions that focus on joint appropriation and provision problems. In earlier related field work, we outlined the institutional framework (Baur and Binder 2013), real-world behavioral determinants (Baur et al. 2014), and game-theory modeling work for the use case (Baur and Nax 2018). All of these works highlight the need for joint investigations of appropriation-provision decisions. Although our field studies on behavioral determinants are characterized by external validity and relatively small sample sizes, they obviously do not allow us to test how various policies affect decision making. The current study is an online experiment, as we intend to study a large number of candidate policy interventions.
Most of the related experimental literature on CPR experiments examine appropriation and provision situations as separate or unlinked (in terms of incentives) sequential decisions. Based on Gordon's fisheries model (Gordon 1954), appropriation games have been developed to mimic the harvesting problem, in which players extract from a common pool and thereby reduce available surplus (Walker et al. 1990). It has been shown that players overappropriate out of short-term self-interest, which can in turn lead to the tragedy of the commons (Gardner et al. 1990, Ostrom et al. 1994). Evidence from the field suggests that cooperative outcomes are possible, and so further experiments then test for conditions that allow for sustainable resource use; their findings suggest that with communication (i.e., cheap talk) or the possibility of sanctioning noncooperative peers, the tragedy can be precluded (Ostrom et al. 1992). More recent work shows that information about resource scarcity (Osés-Eraso and ViladrichGrau 2007, Blanco et al. 2017) or spatial and temporal resource availability (Janssen et al. 2013) helps individuals adjust their appropriation behavior so as to preclude stock depletion.

In turn, the provision problem is often represented as a public good game, where players make private investments in a common stock to generate redistributable surplus. Experimental evidence suggests that a public good cannot be maintained over time without suitable mechanisms such as communication (Isaac and Walker 1988), punishment (Fehr and Gächter 2002), or sanctioning (e.g., Baldassarri and Grossman 2011). These works show that both appropriation and provision problems can be collectively resolved when beneficial institutional traits are present. Despite the large number of CPR and public good games, only a few studies link the two.

An early attempt to formalize joint appropriation and provision situations exists for the case of communal grazing (de Janvry et al. 1998). The authors argue that a resource needs to be established (i.e., the provision problem) before it can be harvested (i.e., the appropriation problem). Based on comparative statics, the results of their formal investigation suggest that the quality of provision (appropriation) depends on appropriation (provision), thus suggesting that these two situations are highly interdependent. The findings deriving from a first line of experimental work on joint appropriation-provision situations suggest that when payoff structures are equal, the provision problem is more likely to be resolved than the appropriation problem (Andreoni 1995, Cox et al. 2013, Gächter et al. 2017). A second line of joint appropriation-provision experiments, conducted mostly in the field, investigated the appropriation-provision problem as sequential decisions, where the resource first needs to be established through generous provision contributions before it can be harvested. This second line of experiments more closely aligns with formalizations of the problem (de Janvry et al. 1998, Baur and Nax 2018) and the experiment reported herein. The main findings are that (i) individuals are willing to make continuously high levels of provision contributions, in spite of being left with fewer resources to harvest because of an unfavorable position, and (ii) individuals with higher appropriation rates compensate with higher contributions in the provision stage (Janssen et al. 2011, 2013, Falk et al. 2016). These findings point to the existence of a "take more, give more" mechanism in individuals that results in behavioral congruence in joint appropriation-provision situations. However, as these experiments used asymmetric positioning in the appropriation 
stage, it remains unclear whether appropriation-provision congruence also holds in the absence of asymmetries.

Our appropriation-provision experiment differs from those found in these works, especially with regard to the decisions sequence. In our experiment, players first appropriate and then provide; we follow that sequence as we mimic the use of an existing resource - and not one that first needs to be established, as in the field games. Furthermore, this sequence more closely aligns with the institutional reality, where players decide on the number of animals to be sent for grazing and then subsequently fulfill (or are derelict in) their provision duties.

\section{METHODS}

\section{From Field to Lab Parameters}

We introduce a novel experimental framework that links appropriation to provision decisions. Our experimental design reflects the case of common property pasture use as observed in Grindelwald, Switzerland, which we exposit elsewhere in greater detail (Baur et al. 2014, Baur and Nax 2018). We made great efforts to parameterize our experiment in a way analogous to the field setting, in terms of decision and payoff structures (Fig. 1).

\section{Group size and endowment}

In the case study region, 126 active farmers organize into seven corporations (i.e., operational units), resulting in an average group size of 21 individuals. On average, each farmer holds 11.6 livestock units (LU) (i.e., cows). For our baseline situation, we therefore endowed players with 10 tokens and placed them in groups of 20 . Each of the seven corporations has its own clearly defined grazing territory with associated infrastructure (e.g., paths, waterprovisioning systems, and fences for collective use) and maintenance through provision activities.

\section{Appropriation and provision}

Each summer, farmers decide how many of their livestock to send for grazing in the common summer pastures (appropriation), or alternatively keep them on private land (private option) (Fig. 1). With regard to appropriation behavior in the field, we observed appropriation levels of $87 \%$ of total endowment, meaning that almost nine out of 10 animals were sent to the common pastures over the summer.

In return for their benefit from appropriation, farmers are bound by local governance to participate in provision activities by which they enhance the common pastures and respective infrastructure; this participation is usually set at $8 \mathrm{~h}$ per $1 \mathrm{LU}$ summered. A previous analysis suggests that the average return generated from summering $1 \mathrm{LU}$ is, on average, five times the (opportunity) costs of the provision effort required per summered LU (Baur et al. 2014). Therefore, we decided to set the institutional provision contribution requirement at $20 \%$ of the tokens previously appropriated. With regard to provision in the field, we observed that overprovision is common; only $8 \%$ conducted less provision than required, whereas $34 \%$ conducted as much provision as required. The majority of farmers $(52 \%)$ conducted more provision than required, for which they are compensated at some fixed rate. A few farmers ( $6 \%$ ) were exempt from provision duties, as they did not appropriate. This self-reported provision behavior was validated through a survey executed by the wardens of the seven corporations (Baur et al. 2014). In summary, our field
Fig. 1. Conceptual framework for the "field-in-the-lab" experimental game. The upper part depicts the real-world appropriation-provision decision setting as observed for the use case. The lower part stylizes the experimental setup for the baseline. Stars symbolize tokens and indicate numerically average behavior and outcomes as observed in the baseline play. Accordingly, farmers placed 4 tokens in the private option, which yielded a constant return of 4 tokens, and appropriated 6 tokens from the common pool. On average, farmers exceeded their $20 \%$ provision suggestion (1.2 tokens) and provided 1.6 tokens. Appropriation below optimal levels is therefore balanced by provisions above the suggestion, resulting in total productivity of the CPR by a factor of 1 . The payoff from using and providing for the common pool is therefore calculated thus: appropriation (6 tokens) times CPR factor (1) minus provision (1.6 tokens). Together with the tokens from the private option, the player stylized in this example earned 8.4 tokens.

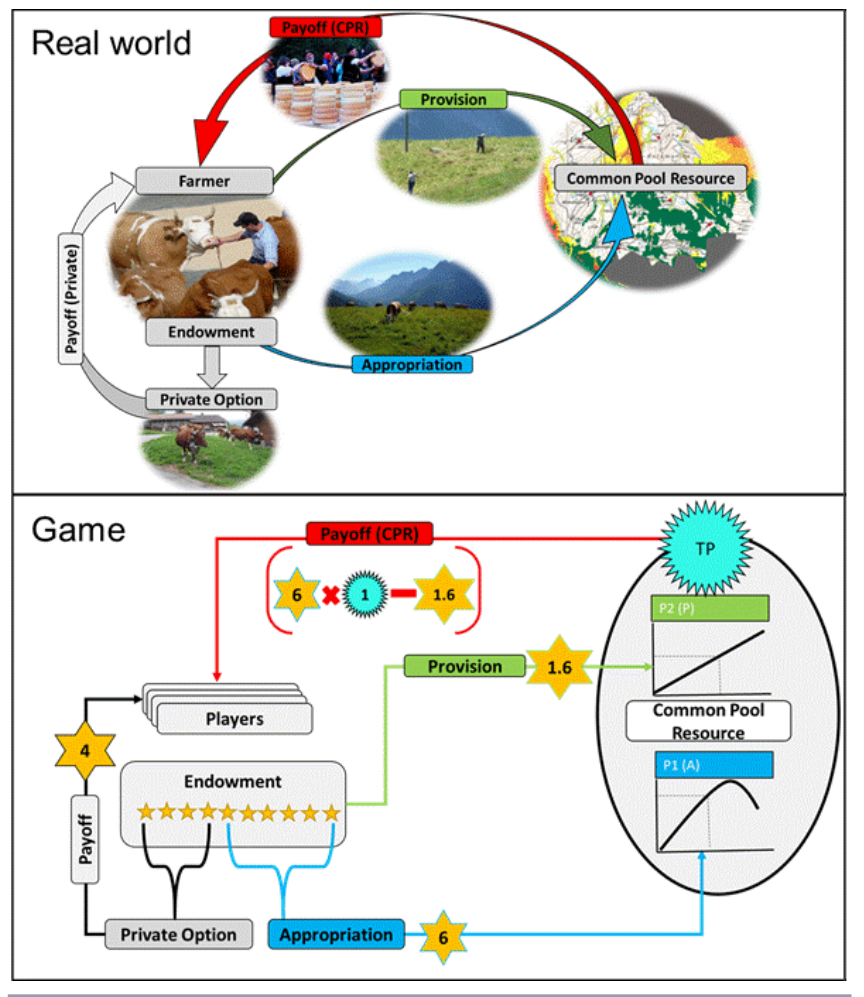

setting constitutes a situation where slight underappropriation and significant overprovision dominate.

\section{Resource productivity}

At the local scale, total livestock present in the valley (1460 LU) slightly exceeds carrying capacity (1348 LU) (see Baur et al. 2014, Baur and $\operatorname{Nax} 2018$ ). Given average appropriation rates of $87 \%$, a total of $1270 \mathrm{LU}$ livestock were sent to the commons; this constitutes a situation of slight undergrazing (i.e., $6 \%$ below carrying capacity/optimality). We accounted for the shortage of common grazing grounds in relation to cattle by setting optimal appropriation levels at $80 \%$ of the group endowment. As such, the resource yields the highest return, per token appropriated, 
when $80 \%$ of total endowments are allocated to the common pool. If that $80 \%$ optimum is not met, either over- or underappropriation lowers resource productivity-and the further from the $80 \%$ target we get, the more productivity is adversely affected. The curvilinear production function accounts for the negative effects of both over- and undergrazing on the resource. To capture the effect of provision duties on the resource, we implemented a linear production function while assuming that each additional token has the same marginal positive effect on the productivity of the resource. (Append. 1 provides further details.)

\section{Payoffs}

It is difficult to isolate the payoffs resulting from sending a cow to the summer pastures vs. keeping it on private lands; to the best of our knowledge, no further considerations exist. For the private option - which is to say, keeping the cow in the barn-we think of payoffs in the form of $U_{p}=M_{p} * \pi_{p}$. Whereas the average daily milk yield $\left(M_{p}\right)$ per LU (including nonlactating animals) is $9 \mathrm{~kg}$, the price obtained $\left(\pi_{p}\right)$ averages $\mathrm{CHF} 0.50$. Hence, the average payoff for the private option is CHF 4.50 per LU, per day.

Payoffs from the common pool option are $U_{c}=\mathrm{M}_{c} * \pi_{c}-\mathrm{F}_{c}$, where $M_{c}$ is $0.8 \mathrm{~kg}$ per day in the form of cheese produced during the summering season, with an average price achieved $\left(\pi_{c}\right)$ of $\mathrm{CHF}$ 18 per $\mathrm{kg}$. Thus, net payoffs are CHF 14.40 per LU, per day. From this, we subtract a fee $F_{c}$ of $\mathrm{CHF} 7$ per day, which is to be paid to herders and cheesemakers for their work. This leaves farmers with an average payoff of CHF 7.30 per LU, per day for the common pool option. Hence, the ratio of payoffs between common and private options is roughly 1.6 (i.e., CHF 7.30 for the commons, divided by CHF 4.50 for the private option). In the experimental setup, we represent this ratio by initially setting the payoffs for tokens allocated to 1 for the private option, and to 1.5 for the common pool option.

\section{The Appropriation-Provision Game}

We modeled the appropriation decision so as to be similar to that in a voluntary contributions game. That is, it is treated as a decision to invest from some individual endowment (i.e., placing it into a common pool option) or not (i.e., placing it into a private option). The common pool option is to send the cow to the common summer pasture; the private option is to keep the cow in the barn. We implemented a controlled online experiment based on the above use case, using the numerical targets from the field (as exposited above). To do so, we implemented the following twostage appropriation-provision game $G(a, p, n)$, which we first introduced and studied analytically in terms of Nash equilibrium predictions (Baur and Nax 2018). This game has two stages, as discussed below.

\section{Stage 1: Appropriation}

In the appropriation stage, each agent $i$ of the population $\mathrm{N}=$ $\{1, \ldots, n\}$ of individuals decides how many of their tokens (endowment $E$ ) to appropriate from the common pool available to them (appropriation $a_{i}$ ). We denote the vector of appropriation decisions as $a$. Naturally, $a_{i} \in[0, E]$. The remaining tokens $\left(E-a_{i}\right)$ are placed in a safe, outside option that yields a constant return of 1 .

\section{Stage 2: Provision}

In the provision stage, it is suggested that each individual provides $\left(p_{i}\right)$ toward the common stock. We denote the vector of provision decisions as $p$. The provision suggestion $p_{i}$ is proportional to the tokens appropriated - which is to say, $p_{i}=a_{i} * k$, where $k=0.2$ in the benchmark, and 0.4 in one treatment. Therefore, a subject appropriating 8 tokens from the common pool will be asked to invest 1.6 tokens in the second stage in return, to improve the productivity of the common pool; players decide about their provision without being informed about aggregate appropriation. The tokens invested in this second provision stage are then subtracted directly from the individual-level payoffs, at a conversion rate of 1 . Therefore, the cost of providing 1 token $C$ $\left(p_{i}\right)$ to ensure the productivity of the common pool is exactly equal to the actual value of 1 token. After both stages are played, payoffs $\left(U_{i}\right)$ for the individual $(i)$ are generated from the private and common options. As mentioned, for each token placed in the safe, private option, the subject receives a constant return (v) normalized to 1 .

The returns from the common pool depend on the overall appropriation and (costly) provision decisions made by individuals $i$ themselves $\left(a_{i}, p_{i}\right)$, and by all agents $\left(A=P_{j \in N} \mathrm{a}_{j}, P=\right.$ $P_{j \in N} \mathrm{p}_{j}$ ). Table 1 in Append. 1 (under "Productivity 1") summarizes the productivity of the resource in terms of a preliminary marginal per capita rate of return as a function of the overall appropriation level $A$. Notice a feature of the resource characteristics, according to which any deviation of $A$ from $M S Y$ at 160 tokens overall, positive or negative, reduces stock productivity. Furthermore, Table A in Append. 1 (under "Productivity 2") summarizes the multiplicative productivity attained as a function of the overall provision level $P$. Notice that any provision contribution increases stock productivity linearly; accordingly, the total return of each token allocated to the common pool is the product of the productivities:

\section{TOTAL PRODUCTIVITY $(a, p)=$ PRODUCTIVITY $1(a) \times$ PRODUCTIVITY $2(p)$}

The final payment for individual $i$ is therefore:

$$
\begin{aligned}
& U_{i}(a, p)= \\
& E-a_{i}+\text { Total Productivity }(a, p) \cdot A-C\left(p_{i}\right)
\end{aligned}
$$

\section{Equilibrium predictions}

As this game is a sequential one, we can obtain Nash equilibrium predictions refined by subgame perfection (for details, see Baur and Nax 2018). Compared with the social optimum-i.e., the levels that maximize resource productivity (see Append. 1) - the subgame perfect Nash equilibria for the parameters in our experiment are characterized by underappropriation and underprovision, resulting in suboptimal resource productivity. ${ }^{[1]}$ Note that the linkage of both decisions via provision requirements that depend on appropriation levels is crucial to obtaining these predictions because, when studied as separate games, the Nash equilibrium predictions are overappropriation and underprovision. The strategic reduction of appropriation to reduce provision duties is the crux here: it was originally (and precisely) the idea to moderate appropriation to optimal levels, but today it leads to below optimum reductions. This, in combination with underprovision (at even lower levels than are optimal), creates the inverse tragedy of the commons, as discussed. 


\section{Treatments}

Subjects played two rounds of the appropriation-provision game. The baseline specification of our appropriation-provision game is always played in the first round; this specification is designed to be in accordance with the current real-world case, previously discussed. Therefore, all players are endowed with 10 tokens and randomly assigned to a group of 20 . They find a common resource that has an initial productivity of 1.5 , whereas the productivity of the private option is 1 . That productivity is maintained if players allocate $80 \%$ of their endowment in stage 1 , and in stage 2 , contribute the suggested $20 \%$ of their appropriated tokens.

In the second round, a different game specification is played depending on the randomly assigned treatment. Only in the "control" treatment is the baseline specification played a second time, which serves as the reference. Other specifications are played that vary all relevant parameters (ceteris paribus), as detailed in Table 1.

Table 1. Treatment variations regarding second-phase appropriation-provision game specifications including smaller group sizes ("small"), larger endowments ("rich"), smaller group and larger endowment ("small-rich"), increased productivities ("productive"), increased institutional provision requirements ("demanding"), and "carrots" (rewarding overprovision) vs. "sticks" (punishing underprovision). Varying parameters are in boldface.

\begin{tabular}{|c|c|c|c|c|c|}
\hline & $\begin{array}{l}\text { Group } \\
\text { (n) }\end{array}$ & $\begin{array}{c}\text { Endowment } \\
\text { (e) }\end{array}$ & $\begin{array}{l}\text { Productivity } \\
\text { (mpcr) }\end{array}$ & $\begin{array}{c}\text { Institution } \\
(\mathrm{k})\end{array}$ & $\begin{array}{c}\text { Inst. change } \\
\mathrm{k}^{*} \mathrm{U}_{\mathrm{i}}\end{array}$ \\
\hline Baseline & 20 & 10 & 1.5 & 0.2 & \\
\hline Small & 10 & 10 & 1.5 & 0.2 & \\
\hline Rich & 20 & 20 & 1.5 & 0.2 & \\
\hline Small-Rich & 10 & 20 & 1.5 & 0.2 & \\
\hline Productive & 20 & 10 & 2 & 0.2 & \\
\hline Demanding & 20 & 10 & 1.5 & 0.4 & \\
\hline Carrots & 20 & 10 & 1.5 & 0.2 & $\dagger$ \\
\hline Sticks & 20 & 10 & 1.5 & 0.2 & $t$ \\
\hline \multicolumn{6}{|c|}{$\begin{array}{l}\dagger \text { : With probability } 0.5 \text { players contributing more than the suggested } 0.2 \text { are } \\
\text { rewarded by doubling their payoffs }(\mathrm{k}=2) \text {. } \\
+ \text { : With probability } 0.5 \text { players contributing less than the suggested } 0.2 \text { are } \\
\text { punished by halving their payoffs }(\mathrm{k}=0.5) \text {. }\end{array}$} \\
\hline
\end{tabular}

The first three treatments in Table 1 vary user attributes, such as group size and endowment. The "small" treatment tests for the effect of smaller operating groups, whereas the "rich" treatment tests for increased endowment; the "small-rich" treatment refers to a situation where larger endowed farmers operate in small groups. The "productive" treatment tests for user behavior when they find a more productive resource. The last three treatments in Table 1 test for the effects of institutional change. "Demanding" mimics a situation in which local governance doubles the provision requirements per appropriated unit. In "carrots," local governance incentivizes overprovision by doubling the payoffs of overproviders with a $50 \%$ chance, and in "sticks," local governance punishes underproviders by halving their payoffs equally with a $50 \%$ chance.

\section{Data collection and subject pool}

Data were collected through ETH Zurich's Decision Science Laboratory using Amazon's Mechanical Turk and a pool of preregistered subjects. The subjects received extensive instructions (Append. 2). On 4 April 2018, we first collected a sample of 100 subjects to test our experimental design in the baseline treatment. After controlling for data quality by checking that we had successfully parametrized the setting to obtain comparable levels - as in our field study - and identifying no technical issues, we recruited another 700 subjects the next day, on 5 April 2018. A total of 800 players played the baseline treatment, and in the second round, we had 104 subjects for each of the different treatments. We recruited no other subjects and ran no other parametrizations, as we were successful at replicating overall levels of the field data in our first parametrization attempt, based on numerical values inspired by the real-use case.

The main advantage of this approach over alternative recruitment strategies is our ability to recruit many subjects at a relatively low cost; we need a large subject pool because we want to test many treatments. Disadvantages include the relatively low stakes and problems of external validity, although we have no reason to suspect that the most standard alternative sampling technique via a university lab (from a student subject pool) would result in better external validity. We believe external validity needs to be addressed in future field and randomized control trial studies.

On average, each subject needed $16 \mathrm{~min}$ to complete the game and the subsequent personal survey; each earned about USD 3.27, including participation and quiz score rewards. The subjects are typical "MTurkers," - that is, individuals located in the United States of America (no major locational clusters were observed) who are accustomed to participating in these kinds of tasks, and who trust the lab host to make payments as promised. The results of the personal survey executed after the game show that the resulting sample was rather gender equal, with the number of male subjects $(52 \%)$ only slightly exceeding that of female subjects $(48 \%)$. The subjects were rather young, with their median age category being 25-34 years (43\%). Their dominant income category was USD $25,000-49,999(35 \%)$. There were more single $(47 \%)$ than married individuals $(46 \%)$. The subjects appeared to be well educated, with $54 \%$ holding a bachelor degree or higher. Surprisingly, the majority of subjects $(59 \%)$ identified themselves as full-time employees. In summary, our sample comprised higher-status individuals in terms of education, income, and employment than we had expected. In addition to the basic sociodemographic information we collected, we presented four statements (e.g., "Everybody should be responsible for his own economic success" and "It is important to give back to the community") and asked for people's level of agreement on a fivepoint Likert scale. Furthermore, we provided statements to control for subject understanding (e.g., "The instructions were clear and easy to understand"), to which individuals also provided responses on a five-point Likert scale. Further details on the questions measuring people's experience with the game are found in Append. 3.

\section{Data Analysis Plan}

Our analysis proceeded in three steps. First, we provided descriptive statistics for the four outcome variables - namely, appropriation, provision, appropriation-provision correlation, and resource productivity - at aggregate levels. Second, we compared treatments in terms of comparing the outcome variables. To test whether treatments differ significantly from each other, we performed a Kruskal-Wallis test, followed by Dunn's 
Fig. 2. Appropriation and provision levels, and resource productivity for a baseline situation and eight treatments. The red reference lines indicate the optimum for appropriation, provision levels, and the initial resource productivity. Note: normalized values displayed in the appropriation graph for the "rich" and "small-rich" treatments and for the "demanding" and "productive" treatments are in the provision graph.
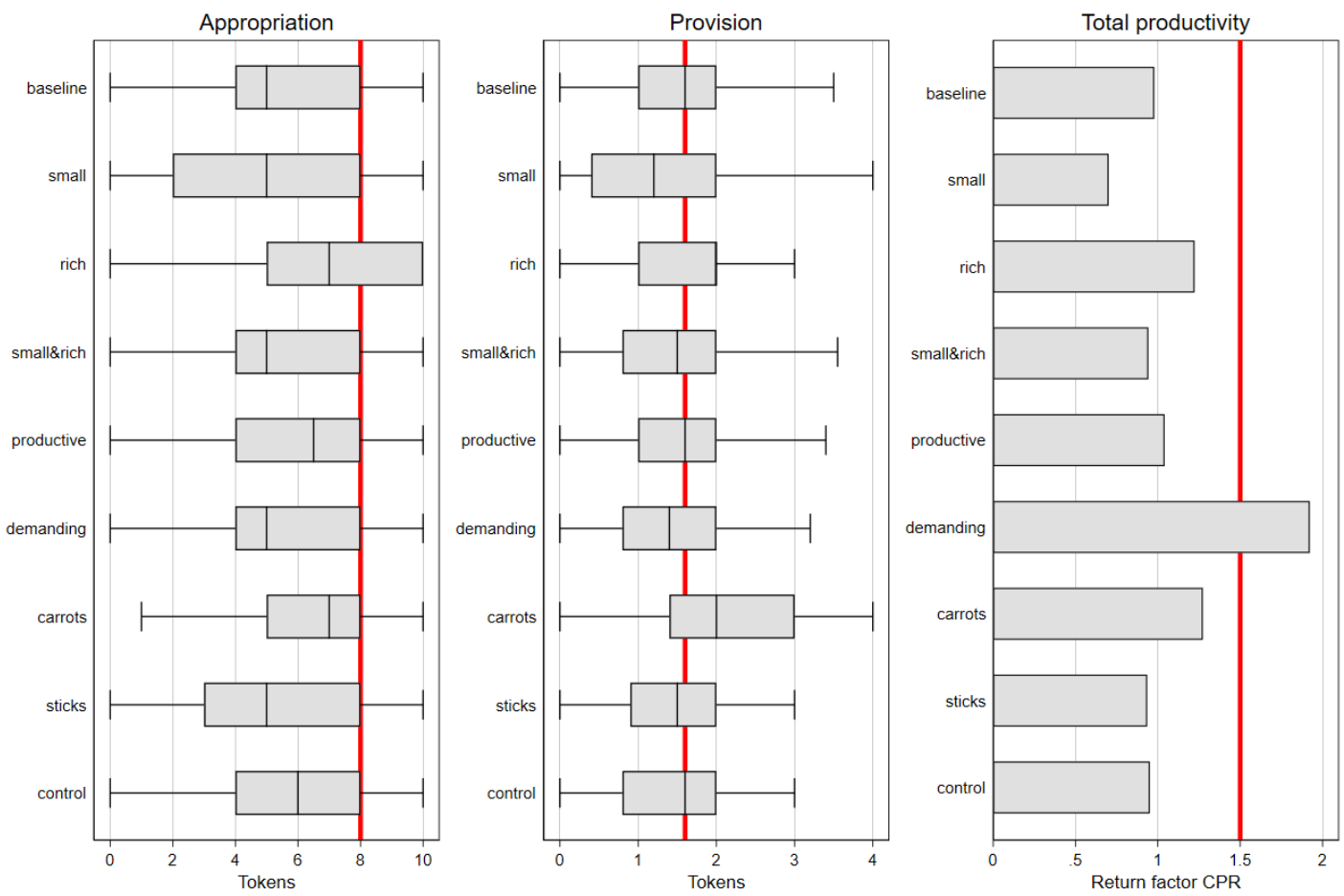

comparison post hoc test, to determine which treatments actually differed from each other according to rank sums. Nonparametric tests were applied because of the nonnormal data distribution. Third, we estimated linear regression models for appropriation and provision behavior, for the baseline and the treatment phases separately. The four regression models aimed, on one hand, to explore which individual-level factors determine appropriation and provision behavior, and on the other, to control whether observed treatment effects are endogenous or relate somewhat to group constellations. To explore individual level determinants, we estimated models based on behavior in the baseline phase, including sociodemographic predictors, norms, quiz scores, and variables controlling for subjects' understanding of the game. To control for group constellations vs. actual treatment effects, we estimated models for the treatment phase, using the same controls; we also included dummies for treatments, with the control treatment serving as the reference. The models were estimated with robust standard errors to address heteroscedasticity. For the estimates of the provision model, we omitted a few influential outliers to achieve the normal residuals distribution.

\section{RESULTS}

Aggregate Statistics and Validation vis-à-vis Field Data

Appropriation levels in the experiment reflected those observed in our field study. In the field setting, appropriations were $6 \%$ below the optimum, whereas appropriation in our baseline treatment remained $17 \%$ below the optimum. The treatment with the highest appropriation levels (i.e., "rich" still generated appropriation levels $6 \%$ below optimum, corresponding precisely to field levels. On the low end, the "small" treatment-which tested for reduced group size-generated the smallest appropriation levels, with levels 37\% below optimum (see Fig. 2, left side).

Provision levels generally exceeded the requirements analogous to our field case. Despite appropriations in all treatments falling below optimality, the provision levels roughly matched the average 1.6-token contribution needed to maintain resource productivity (see Fig. 2, middle). Exemplarily, the baseline treatment resulted exactly in the provision levels needed to maintain the resource, even though appropriation levels were below optimum. (Recall that the provision suggestion was conditional on appropriation.) Similarly, in many other treatments, the productivity of the stock increased through the provision contributions made in stage 2, as provision contributions exceeded the 1.6-token per player threshold (i.e., 32 tokens per group). Regarding treatments, the highest provision levels triggered the treatment potentially rewarding overprovision (i.e., "carrots"). Furthermore, an increase in endowments ("rich" and "small-rich") and an increase in initial resource productivity ("productive") also led to higher provision levels. The treatment in which the provision suggestion 
Table 2. Descriptive statistics and Dunn's pairwise comparison of treatments outcomes. Groups with different letters indicate significant differences between rank orders at alpha $=0.05$.

\begin{tabular}{|c|c|c|c|c|c|c|c|c|c|c|c|}
\hline & \multirow[b]{2}{*}{$\mathrm{n}$} & \multicolumn{3}{|c|}{ Appropriation } & \multicolumn{3}{|c|}{ Provision } & \multicolumn{2}{|c|}{ Correlation } & \multicolumn{2}{|c|}{ Productivity } \\
\hline & & Mean & Mdn & Group & Mean & Mdn & Group & Mean/Mdn & Group & Mean/Mdn & Group \\
\hline Baseline & 817 & 5.80 & 5 & $\mathrm{~b}$ & 1.62 & 1.6 & $\mathrm{a}$ & 0.67 & $\mathrm{e}$ & 0.98 & $\mathrm{~d}$ \\
\hline Small & 103 & 5.04 & 5 & $\mathrm{c}$ & 1.32 & 1.2 & $\mathrm{~b}$ & 0.70 & $\mathrm{~d}$ & 0.70 & $\mathrm{~h}$ \\
\hline Rich & 101 & 6.72 & 7 & $\mathrm{a}$ & 1.81 & 2 & $\mathrm{a}$ & 0.67 & $\mathrm{f}$ & 1.22 & $\mathrm{c}$ \\
\hline Small-rich & 103 & 5.69 & 5 & bc & 1.58 & 1.5 & $\mathrm{ab}$ & 0.81 & $\mathrm{a}$ & 0.94 & f \\
\hline Productive & 102 & 6.11 & 6.5 & $a b$ & 1.65 & 1.6 & $\mathrm{a}$ & 0.71 & $\mathrm{~cd}$ & 1.04 & $\mathrm{c}$ \\
\hline Demanding & 102 & 5.95 & 5 & $\mathrm{~b}$ & 1.55 & 1.4 & $\mathrm{a}$ & 0.75 & $\mathrm{c}$ & 1.92 & $\mathrm{a}$ \\
\hline Carrots & 103 & 6.15 & 7 & $a b$ & 2.01 & 2 & $\mathrm{a}$ & 0.70 & $\mathrm{~d}$ & 1.27 & b \\
\hline Sticks & 101 & 5.70 & 5 & $\mathrm{bc}$ & 1.56 & 1.5 & $\mathrm{a}$ & 0.76 & bc & 0.93 & $\mathrm{~g}$ \\
\hline Control & 102 & 5.98 & 6 & $\mathrm{~b}$ & 1.53 & 1.6 & $\mathrm{a}$ & 0.77 & $\mathrm{~b}$ & 0.95 & $\mathrm{e}$ \\
\hline
\end{tabular}

Note. Values normalized to correspond with the baseline and control setting.

had increased ("demanding") did result in a rather lower relative provision, but in absolute terms, it was still clearly higher than that of other treatments.

The baseline treatment resulted in a resource productivity of 0.98 (see Fig. 2, right hand); this indicated that the productivity of the common pool could not be maintained, mainly due to underappropriation. Overall, three treatments led to reduced resource productivity - for some, to levels even below that of the private option. Four treatments resulted in a resource productivity that exceeded factor 1 , meaning that they would provide higher returns than the private option. Clearly, the "demanding" treatment achieved the highest productivity, because of the higher net provision. In fact, "demanding" appeared to be the only treatment in which the productivity of the resource increased relative to its initial state.

The correlation between appropriation and provision was fairly strong, with the Pearson's correlation coefficient $r$ exceeding 0.6 in all specifications (Fig. 3). These solid, positive correlations indicated a robust congruence between appropriation and provision behavior. Considering that strong negative correlation coefficients would result from noncooperative behavior (i.e., overappropriation and underprovision), we surprisingly found a high willingness to contribute, relative to appropriation levels. Above all, the "small-rich" treatment achieved the highest correlation, which suggested that smaller groups with increased endowment showed higher commitments in fulfilling provision requirements. Furthermore, we found that almost all treatment variations, including "control," led to increased congruence in appropriation and provision, compared with the baseline (see Fig. 3 ). This finding suggested that congruence in the appropriation decision would likely increase over time with additional rounds played.

\section{Treatment Comparison}

The results of the Kruskal-Wallis test with ties showed that treatments differed significantly with regard to the outcome variables. For appropriation, rank sums differed significantly by $X^{2}(8)=19.37(p=0.013)$; for provision $X^{2}(8)=31.70(p<0.001)$, total productivity with equal $X^{2}(8)=1425.69(p<0.001)$ rank sums differed even more significantly.

Dunn's post hoc test allowed us to cluster treatments into significantly different groups, based on rank sums (Table 2).
Regarding appropriation, small groups with large endowments ("rich") generated the highest appropriation levels, and in this respect, they differed significantly from all other treatments save for "productive" and "carrots." The treatment with reduced group size ("small") resulted in the lowest appropriation levels, and in this respect, differed significantly from all other treatments; the implications are that increasing endowment leads to higher appropriation levels, whereas reducing group size reduces appropriation. The provision levels were highest in the "carrots" treatment, followed by "rich," "small-rich," "productive," "sticks," "baseline," and "control," all of which showed rank sums significantly higher than those in the "small" treatment. The "small-rich" and "demanding" treatments also showed rather low provision levels, but neither was significantly different from the best ("carrots") or the lowest ("small") treatment (Table 2).

In terms of the appropriation-provision correlation, we found that the treatment with the smaller group size and a large endowment (i.e., "small-rich") resulted in the strongest correlation between appropriation and provision levels; this correlation was significantly stronger than that in any of the other treatments. The weakest correlation was in the baseline treatment ("baseline") and with the increased endowment treatment ("rich").

Finally, the total productivity of CPR differed significantly across almost all the treatments. "Demanding" achieved by far the highest total productivity, with a factor of 1.92; this suggested that the state of the resource could be improved relative to its initial state. For this treatment, the increase in provision requirements resulted in higher net provision and did not trigger major defections on provision. The "rich" and "carrots" treatments produced the next-highest CPR productivity levels. Although increasing endowments stimulated higher appropriation levels (as in "rich"), incentives to overprovide resulted in increased provision activities (as in "carrots"); this led in both cases to significantly higher total productivity compared with the baseline, the control specifications, and the private option. The "small" treatment showed the sharpest drop in productivity, with a final total productivity of 0.70 ; the suggestion here was that low endowed individuals in small groups tend reduce the use of the CPR beyond sustainable levels. 


\section{Behavioral Strategies}

Underappropriation appeared to be the most prevalent form of behavior in the appropriation stage. In $59 \%$ of the decisions made, appropriation fell below the optimum (denoted in Fig. 3 by hollow circles and hollow triangles), whereas $41 \%$ of the players appropriated $80 \%$ or more of their endowment (denoted in Fig. 3 by solid circles and solid triangles). With regard to provision behavior, we found that $97 \%$ of the contributions matched or exceeded provision requirements (denoted in Fig. 3 by triangles). Therefore, the most common behaviors were underappropriation and overprovision $(57 \%)$, followed by overappropriation and overprovision $(40 \%)$. Typical freerider behavior suggested by theory-namely, overappropriation and underprovision-was observed in only $1 \%$ of the players, and underappropriation and underprovision was played by $2 \%$ of the players (see Fig. 4 , hollow and solid circles).

Fig. 4. Frequency distribution of four strategies played. Circles denote underprovison strategies, and triangles denote overprovision strategies. Underappropriation in combination with overprovision was the predominant strategy.

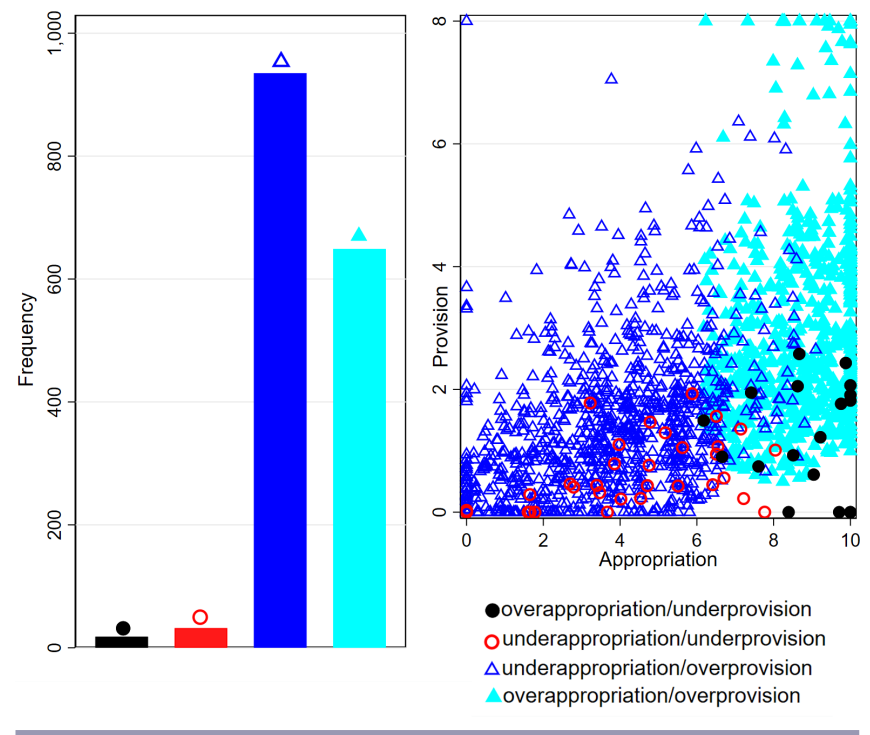

Individual and Treatment Effects

Decisions were not relevantly determined by sociodemographic variables: only age led to a slightly increased appropriation in the baseline model. Other situational variables (e.g., quiz score, experience, level of enjoyment, and norms) determined behavior more significantly (Table 3). Higher quiz scores (i.e., questions that tested understanding of the game) were associated with higher appropriation and provision levels, suggesting that an understanding of the game led people to invest in a potentially more profitable but also riskier option. Furthermore, we found that perceived complexity and understanding of the game slightly affected provision decisions, and this suggested that a better understanding of the game possibly led to slightly increased appropriation and provision activities.
Table 3. Linear regression models estimated with robust standard errors exploring determinants appropriation and provision behaviors. Models are separately estimated for the baseline and the treatment phase. In the treatment models, the control treatment serves as a reference category.

\begin{tabular}{|c|c|c|c|c|}
\hline & \multicolumn{2}{|c|}{ Appropriation } & \multicolumn{2}{|c|}{ Provision } \\
\hline & Baseline & Treatment & Baseline & Treatment \\
\hline \multirow[t]{3}{*}{ Age } & $0.22 * *$ & 0.04 & 0.01 & 0.01 \\
\hline & $(0.09)$ & $(0.09)$ & $(0.03)$ & $(0.03)$ \\
\hline & [0.09] & {$[0.02]$} & {$[0.02]$} & {$[0.02]$} \\
\hline \multirow[t]{3}{*}{ Income } & 0.01 & 0.02 & 0.00 & -0.01 \\
\hline & $(0.09)$ & $(0.09)$ & $(0.03)$ & $(0.03)$ \\
\hline & {$[0.00]$} & {$[0.01]$} & {$[0.00]$} & {$[-0.01]$} \\
\hline \multirow[t]{3}{*}{ Education } & 0.04 & -0.00 & 0.01 & 0.00 \\
\hline & $(0.06)$ & $(0.06)$ & $(0.02)$ & $(0.02)$ \\
\hline & {$[0.02]$} & {$[-0.00]$} & {$[0.02]$} & {$[0.00]$} \\
\hline \multirow[t]{3}{*}{ Quiz score } & $1.11^{* * *}$ & $0.66^{*}$ & $0.22 *$ & 0.17 \\
\hline & $(0.36)$ & $(0.35)$ & $(0.12)$ & $(0.13)$ \\
\hline & {$[0.11]$} & {$[0.06]$} & {$[0.06]$} & {$[0.05]$} \\
\hline \multirow[t]{3}{*}{ Norms (self vs. group) } & $-0.20 * * *$ & $-0.14 * * *$ & $-0.05 * * *$ & $-0.05 * * *$ \\
\hline & $(0.05)$ & $(0.05)$ & $(0.02)$ & $(0.02)$ \\
\hline & {$[-0.14]$} & {$[-0.10]$} & {$[-0.10]$} & {$[-0.10]$} \\
\hline \multirow[t]{3}{*}{ Clarity of instructions } & -0.13 & -0.21 & 0.06 & 0.00 \\
\hline & $(0.12)$ & $(0.13)$ & $(0.04)$ & $(0.05)$ \\
\hline & {$[-0.05]$} & {$[-0.08]$} & {$[0.07]$} & {$[0.00]$} \\
\hline \multirow[t]{3}{*}{ Perceived complexity } & -0.14 & 0.01 & $0.08 * *$ & $0.09 * *$ \\
\hline & $(0.10)$ & $(0.11)$ & $(0.04)$ & $(0.04)$ \\
\hline & {$[-0.05]$} & {$[0.00]$} & {$[0.08]$} & [0.09] \\
\hline \multirow[t]{3}{*}{ Understood logic } & 0.06 & 0.20 & 0.08 & $0.10^{*}$ \\
\hline & $(0.14)$ & $(0.15)$ & $(0.05)$ & $(0.05)$ \\
\hline & {$[0.02]$} & {$[0.07]$} & {$[0.08]$} & {$[0.10]$} \\
\hline \multirow[t]{3}{*}{ Experience } & $-0.25^{* *}$ & $-0.21^{* *}$ & -0.04 & -0.02 \\
\hline & $(0.10)$ & $(0.10)$ & $(0.03)$ & $(0.04)$ \\
\hline & {$[-0.09]$} & {$[-0.08]$} & {$[-0.05]$} & {$[-0.02]$} \\
\hline \multirow[t]{3}{*}{ Enjoyment } & $0.49 * * *$ & $0.61 * * *$ & $0.12 * * *$ & $0.18 * * *$ \\
\hline & $(0.11)$ & $(0.12)$ & $(0.04)$ & $(0.04)$ \\
\hline & {$[0.17]$} & {$[0.21]$} & {$[0.12]$} & {$[0.18]$} \\
\hline \multirow[t]{3}{*}{ Small } & & $-0.97 * *$ & & -0.17 \\
\hline & & $(0.40)$ & & $(0.13)$ \\
\hline & & {$[-0.11]$} & & {$[-0.06]$} \\
\hline \multirow[t]{3}{*}{ Rich } & & 0.63 & & $0.31 * *$ \\
\hline & & $(0.42)$ & & $(0.13)$ \\
\hline & & {$[0.07]$} & & {$[0.10]$} \\
\hline \multirow[t]{3}{*}{ Small-rich } & & -0.27 & & 0.09 \\
\hline & & $(0.39)$ & & $(0.14)$ \\
\hline & & {$[-0.03]$} & & {$[0.03]$} \\
\hline \multirow[t]{3}{*}{ Productive } & & 0.24 & & 0.21 \\
\hline & & $(0.40)$ & & $(0.13)$ \\
\hline & & [0.03] & & {$[0.07]$} \\
\hline Demanding & & 0.01 & & 0.07 \\
\hline & & $(0.40)$ & & $(0.13)$ \\
\hline & & {$[0.00]$} & & {$[0.02]$} \\
\hline Carrots & & 0.12 & & $0.50 * * *$ \\
\hline & & $(0.39)$ & & $(0.14)$ \\
\hline & & {$[0.01]$} & & {$[0.16]$} \\
\hline Sticks & & -0.23 & & 0.12 \\
\hline & & $(0.39)$ & & $(0.13)$ \\
\hline & & {$[-0.03]$} & & {$[0.04]$} \\
\hline Constant & $3.63^{* * *}$ & $3.61 * * *$ & 0.37 & 0.12 \\
\hline & $(0.80)$ & $(0.87)$ & $(0.27)$ & $(0.28)$ \\
\hline & {$[]$.} & {$[]$.} & {$[]$.} & {$[]$.} \\
\hline Observations & 817 & 817 & 812 & 809 \\
\hline $\mathrm{r}^{2}$ & 0.107 & 0.957 & 0.059 & 0.980 \\
\hline Adjusted $\mathrm{r}^{2}$ & 0.096 & 0.077 & 0.047 & 0.079 \\
\hline $\mathrm{F}$ & 11.38 & 5.26 & 5.35 & 6.08 \\
\hline RMSE & 2.79 & 2.86 & 0.98 & 0.99 \\
\hline
\end{tabular}

Robust standard errors in parentheses. Standardized coefficients in square brackets.

$* * * \mathrm{p}<0.01, * * \mathrm{p}<0.05,{ }^{*} \mathrm{p}<0.1$ 
Fig. 3. Correlations between appropriation and provision behavior across a baseline specification and eight treatments.

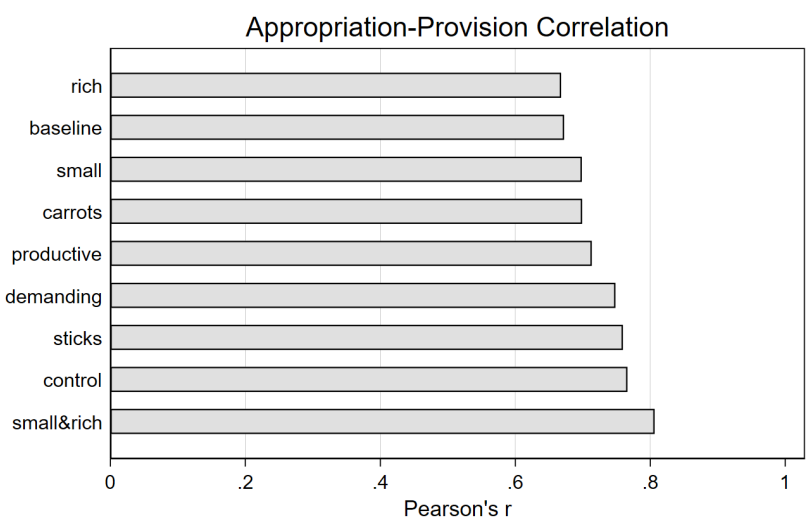

However, norms (measuring a self vs. group orientation) appeared to be the most influential determinant, as indicated by the standardized beta coefficients of the regression models. Accordingly, self-orientation led to reduced appropriation and provision levels, showing that more self-oriented individuals prefer the secure private option, whereas group-oriented individuals tended to prefer the riskier collective option. Individuals reportedly experienced with this type of game also showed lower appropriation levels, suggesting that they had possibly already learned that it is beneficial to apply selfish strategies in public good contribution situations. Interestingly, higher levels of enjoyment quite strongly associated with increased appropriations and provision levels.

As suggested by the appropriation models for the treatment phase, we found that individuals placed in smaller groups ("small") reduced appropriation significantly (i.e., by almost 1 token) relative to the control treatment. In contrast, individuals with larger endowments (as in the "rich" treatment) increased appropriation by 0.63 tokens. Although the difference in appropriation between "rich" and "control" was merely nonsignificant in the regression model, we are confident that an increase in endowment would trigger higher appropriation levels (as observed in the treatment comparison) and would not relate merely to potential subject heterogeneity across treatments.

With regard to provision, the model results suggested that two treatments, "carrots" and "rich," each led to a significant increase in provision contributions, of 0.5 and 0.3 tokens, respectively; these findings corresponded to actual differences in provision levels. As the model estimates for treatment effects corresponded largely to actual behavioral differences, we are confident that observed changes in appropriation and provision behavior were indeed attributable to simulated changes in individual-level endowment and institutions, and not caused accidently by subject heterogeneity across treatment groups. Clearly, the models left unexplained much of the variance indicated by the low $r^{2}$ values; however, the aim of the models was not to find the individual attributes that allow for the most adequate behavioral predictions, but to isolate the role of the treatments in triggering behavioral change - something for which the predictive power of the models was rather irrelevant.

\section{DISCUSSION AND CONCLUSION}

Many high nature value farming systems (HNVFS) - in particular, Alpine summer grazing pastures-are managed as commons. Across Europe, these commons have transitioned from being scarce and prone to overuse to resources of marginal economic benefit. Many ecologically valuable grazing commons risk being underused and abandoned, despite there being agricultural subsidies and conservation measures (Bieling 2013). As these HNVFS coproduce important habitats, biodiversity, and unique cultural landscapes, gradual abandonment or even collapse call for countermeasures. To that end, conventional agricultural policies featuring higher subsidy levels are not necessarily the best means of stewardship; indeed, locally based approaches are more promising options (Plieninger and Bieling 2013).

The current study was undertaken in the search for locally based governance approaches with which to better cope with reduced common pool resource (CPR) use. More specifically, we investigated how appropriation relates to provision behavior when these two decisions are institutionally interlinked, and what institutional adaptations might lead to more sustainable resource use. Consequently, in a controlled experiment, we replicated a Swiss Alps field case from Grindelwald's summer pastures. The summer pastures in Switzerland are a typical case of highly valuable ecological agricultural landscapes that provide only marginal returns and are thus increasingly subject to underuse and abandonment. In the field, we saw that cooperative strategies of underappropriation in combination with overprovision dominate. We parametrized the experiment so that the exact same behavioral strategies dominated also in our experiment (in the baseline and control treatment). Our findings completely contradicted naive game theory predictions obtained by studying appropriation and provision separately, which instead predict overappropriation and underprovision. However, as to provision levels, our findings also contradicted the more sophisticated predictions obtained for the combined sequential game (i.e., underappropriation and underprovision). This indicated that cooperation is likely to be higher in the provision stage than in the appropriation stage, and was in turn indicative of a sense of responsibility that prevails among individuals to contribute to the maintenance of a resource and compensate proportionally for what they have extracted. This inference is in line with observations that, in institutionally linked appropriationprovision settings, provision contributions are somewhat likely to relate to appropriation levels, as holds under voluntary contribution mechanisms (Andreoni 1995, Gächter et al. 2017). Furthermore, our findings confirmed that congruence between appropriation and provision rules is crucial to achieving sustainable CPR use - as highlighted in meta studies by Ostrom (1990) and Cox et al. (2010) — and to defining the properties of successful CPR governance.

Regarding the observed variation in appropriation and provision decisions - as per our experimental variation vis-à-vis the field case - we found that higher appropriation levels correlate with larger provision contributions, even in the absence of provisiondefection sanctions. Hence, policies should aim to stimulate 
appropriation and provision. In terms of appropriation, our analytical results suggested that as endowment increases (as in the "rich" treatment), individuals tend to use the CPR more intensely. In terms of provision, stronger incentives ("carrots") and higher provision requirements ("demanding") are the two most effective policies, with "carrots" outperforming "sticks." Strong appropriation and net provision levels then manifested in higher productivity, with "demanding" achieving by far the highest CPR productivity, followed by "carrots" and "rich"both of which still led to much higher productivity than the "baseline" and "control" specifications.

\section{Limitations and Outlook}

We believe that our findings represent important first steps toward identifying candidates for institutional adaptations by which the government can manage abandonment-prone common grazing lands. For our Grindelwald field case, we identified as the most natural randomized control trial (RCT) an intervention at the local governance level that featured increased provision requirements. Although we sought to interpret our findings immediately in terms policy avenues, we believe that an empirically justified RCT is a necessary next step. Despite our best attempts to blend field and lab approaches, there remains considerable divergence between field and lab, given differences in subject pools, the payoffs at stake, and the nonfield nature of online experiments. For this reason, we did not expend additional effort to gather data that would otherwise have allowed us to better determine the interpersonal drivers of appropriation and provision behavior: we doubted that the subject pool used herein would allow us to make generalizations vis-à-vis the behavioral drivers of real CPR users in the field. Nevertheless, to address this important question, the experiment could be repeated with real CPR users, and accompanied by an updated and more extensive personal survey.

However, in the baseline situation of our experiment, we successfully replicated behavior in the field, and we isolated the most promising effects, ceteris paribus - namely, "demanding," "carrots," and "rich"-from a relatively long list of candidates. What limits the external validity of our study is the nonrepeated nature of our experiment; this serves as an avenue for future experimental research by which to test whether the promising policy candidates identified here for the short term could also deliver more sustainable outcomes in the long term. We are hopeful that such work will complement more applied work toward identifying promising institutional adaptations and counteract the abandonment of commonly managed high nature value grazing lands, in Grindelwald and elsewhere in Europe.

\footnotetext{
${ }^{[1]}$ We approximate subgame perfect Nash equilibrium predictions for our experimental parametrization by using predictions derived from the (continuous) model of Baur and Nax (2018); we validate which action profiles in our discretized setting correspond numerically to the equilibrium.
}

Responses to this article can be read online at: https://www.ecologyandsociety.org/issues/responses. php/12140

\section{Acknowledgments:}

We are grateful for guidance by Jimmy Walker and for comments that helped improve the paper by anonymous reviewers and editors at Ecology and Society of the Special Feature on High Nature Value Farming Systems in Europe, as well as by seminar participants at the Ostrom Workshop in Bloomington and the Human Dimensions of Environmental Risks Conference in Monte Verita. The authors thankfully acknowledge support from the Swiss National Science Foundation through a Mobility grant (IB) and an Eccellenza grant (HHN). Last but not least, we thank Oliver Braegger and Stefan Wehrli for lab assistance through ETH DeSciL.

\section{Data Availability:}

Data: The analysis uses quantitative date from an original appropriation-provision game conducted with subjects recruited from Amazon MTurk. The data from this study are available fully anonymized from the OSF data repository in the project folder Experiment 1.0: https://osf.ioly2dfr/ Code: The corresponding STATA and R scripts used to analyze the data are equally available from the OSF data repository in the same folder: https:/losf.iol y2dfr/ Ethical clearance: The project and study design was approved by the German Association for Experimental Economic Research on 02/05/2018. Furthermore, the experiment was approved by the review board of the ETH Zurich Decisions Science Laboratory (http://www.descil.ethz.ch), where the experiment was administered. Licensing: The project has been assigned a unique identifier: DOI 10.17605/OSF.IO/Y2DFR, and is licensed under the creative commons: CC-By Attribution 4.0 International.

\section{LITERATURE CITED}

Andreoni, J. 1995. Warm-glow versus cold-prickle: the effects of positive and negative framing on cooperation in experiments. The Quarterly Journal of Economics 110(1):1-21. https://doi. org/10.2307/2118508

Baland, J.-M., and J.-P. Platteau. 1996. Halting degradation of natural resources: is there a role for rural communities? Food and Agriculture Organization of the United Nations, Rome, Italy.

Baldassarri, D., and G. Grossman. 2011. Centralized sanctioning and legitimate authority promote cooperation in humans. Proceedings of the National Academy of Sciences 108 (27):11023-11027. https://doi.org/10.1073/pnas.1105456108

Baur, I., and C. R. Binder. 2013. Adapting to socioeconomic developments by changing rules in the governance of common property pastures in the Swiss Alps. Ecology and Society 18(4). https://doi.org/10.5751/ES-05689-180460

Baur, I., K. Liechti, and C. Binder. 2014. Why do individuals behave differently in commons dilemmas? The case of alpine farmers using common property pastures in Grindelwald, Switzerland. International Journal of the Commons 8(2):657-685. https://doi.org/10.18352/ijc.469

Baur, I., and H. H. Nax. 2018. Adapting governance incentives to avoid common pool resource underuse: the case of Swiss summer pastures. Sustainability 10(11):3988. https://doi. org/10.3390/su10113988 
Bieling, C. 2013. Perceiving and responding to gradual landscape change at the community level: insights from a case study on agricultural abandonment in the Black Forest, Germany. Ecology and Society 18(2): 36. https://doi.org/10.5751/ES-05590-180236

Blanco, E., T. Haller, and J. M. Walker. 2017. Externalities in appropriation: responses to probabilistic losses. Experimental Economics 20(4):793-808. https://doi.org/10.1007/s10683-017-9511$\underline{\mathrm{X}}$

Burt, O. R. 1964. Optimal resource use over time with an application to ground water. Management Science 11(1):80-93. https://doi.org/10.1287/mnsc.11.1.80

Casari, M. 2007. Emergence of endogenous legal institutions: property rights and community governance in the Italian Alps. Journal of Economic History 67(1):191-226. https://doi. org/10.1017/S0022050707000071

Cox, J. C., E. Ostrom, V. Sadiraj, and J. M. Walker. 2013. Provision versus appropriation in symmetric and asymmetric social dilemmas. Southern Economic Journal 79(3):496-512. https://doi. org/10.4284/0038-4038-2012.186

Cox, M., G. Arnold, and S. V. Tomás. 2010. A review of design principles for community-based natural resource management. Ecology and Society 15(4): 38. https://doi.org/10.5751/ ES-03704-150438

de Janvry, A., N. McCarthy, and E. Sadoulet. 1998. Endogenous provision and appropriation in the commons. American Journal of Agricultural Economics 80(3):658-664. https://doi.org/10.2307/1244576

Dietz, T., E. Ostrom, and P. C. Stern. 2003. The struggle to govern the commons. Science 302(5652):1907-1912. https://doi. org/10.1126/science.1091015

Falk, T., D. Lohmann, and N. Azebaze. 2016. Congruence of appropriation and provision in collective water provision in Central Namibia. International Journal of the Commons 10 (1):71-118. https://doi.org/10.18352/ijc.583

Fehr, E., and S. Gächter. 2002. Altruistic punishment in humans. Nature 415(6868):137-140. https://doi.org/10.1038/415137a

Gächter, S., F. Kölle, and S. Quercia. 2017. Reciprocity and the tragedies of maintaining and providing the commons. Nature Human Behaviour 1(9):650-656. https://doi.org/10.1038/s41562-017-0191-5

Gardner, R., E. Ostrom, and J. M. Walker. 1990. The nature of common-pool resource problems. Rationality and Society 2 (3):335-358. https://doi.org/10.1177/1043463190002003005

Gordon, H. S. 1954. The economic theory of a common-property resource: the fishery. The Journal of Political Economy. 62 (2).124-142. https://doi.org/10.1086/257497

Hardin, G. 1968. The tragedy of the commons. Science 162:1243-1248. https://doi.org/10.1126/science.162.3859.1243

Isaac, R. M., and J. M. Walker. 1988. Group size effects in public goods provision: the voluntary contributions mechanism. The Quarterly Journal of Economics 103(1):179-199. https://doi. org/10.2307/1882648
Janssen, M. A., J. M. Anderies, and J.-C. Cardenas. 2011. Headenders as stationary bandits in asymmetric commons: comparing irrigation experiments in the laboratory and the field. Ecological Economics 70(9):1590-1598. https://doi.org/10.1016/j.ecolecon.2011.01.006

Janssen, M. A., F. Bousquet, J.-C. Cardenas, D. Castillo, and K. Worrapimphong. 2013. Breaking the elected rules in a field experiment on forestry resources. Ecological Economics 90:132-139. https://doi.org/10.1016/j.ecolecon.2013.03.012

Keenleyside, C., G. Beaufoy, G. Tucker, and G. Jones. 2014. High nature value farming throughout EU-27 and its financial support under the CAP. Institute for European Environmental Policy, London, UK.

Keenleyside, C., G. Tucker, and A. McConville. 2010. Farmland abandonment in the EU: an assessment of trends and prospects. Institute for European Environmental Policy, London, UK.

Landolt, G., and T. Haller. 2015. Alpine common property institutions under change: conditions for successful and unsuccessful collective action by alpine farmers in the canton of Grisons, Switzerland. Human Organization 74(1):100-111. https://doi.org/10.17730/humo.74.1.x55m464806q67156

MacDonald, D., J. R. Crabtree, G. Wiesinger, T. Dax, N. Stamou, P. Fleury, J. G. Lazpita, and A. Gibon. 2000. Agricultural abandonment in mountain areas of Europe: environmental consequences and policy response. Journal of Environmental Management 59(1):47-69. https://doi.org/10.1006/jema.1999.0335

Netting, R. M. 1976. What Alpine peasants have in common: observations on communal tenure in a Swiss village. Human Ecology (4):135-149. https://doi.org/10.1007/978-1-4757-9584-4_9

Netting, R. M. 1981. Balancing on an Alp: ecological change and continuity in a Swiss mountain community. Cambridge University Press, Cambridge, UK.

O'Rourke, E., M. Charbonneau, and Y. Poinsot. 2016. High nature value mountain farming systems in Europe: case studies from the Atlantic Pyrenees, France and the Kerry Uplands, Ireland. Journal of Rural Studies 46:47-59. https://doi. org/10.1016/j.jrurstud.2016.05.010

Osés-Eraso, N., and M. Viladrich-Grau. 2007. Appropriation and concern for resource scarcity in the commons: an experimental study. Ecological Economics 63(2-3):435-445. https://doi. org/10.1016/j.ecolecon.2006.11.016

Ostrom, E. 1990. Governing the commons: the evolution of institutions for collective action. Cambridge University Press, Cambridge, UK.

Ostrom, E., R. Gardner, J. Walker, J. M. Walker, and J. Walker. 1994. Rules, games, and common-pool resources. University of Michigan Press, Ann Arbor, Michigan, USA. https://doi. org/10.3998/mpub.9739

Ostrom, E., J. Walker, and R. Gardner. 1992. Covenants with and without a sword: self-governance is possible. American Political Science Review 86(2):404-417. https://doi.org/10.2307/1964229

Penker, M. 2009. Landscape governance for or by the local population? a property rights analysis in Austria. Land Use Policy 26(4):947-953. https://doi.org/10.1016/j.landusepol.2008.11.007 
Plieninger, T., and C. Bieling. 2013. Resilience-based perspectives to guiding high-nature-value farmland through socioeconomic change. Ecology and Society 18(4): 20. https://doi.org/10.5751/ ES-05877-180420

Stevenson, G. G. 2005. Common property economics: a general theory and land use applications. Cambridge University Press, Cambridge, UK. https://doi.org/10.1017/CBO9780511528361

van Gils, H., G. Siegl, and R. M. Bennett. 2014. The living commons of West Tyrol, Austria: lessons for land policy and land administration. Land Use Policy 38:16-25. https://doi. org/10.1016/j.landusepol.2013.10.011

Verburg, P. H., D. B. van Berkel, A. M. van Doorn, M. van Eupen, and H. A. van den Heiligenberg. 2010. Trajectories of land use change in Europe: a model-based exploration of rural futures. Landscape Ecology 25(2):217-232. https://doi.org/10.1007/ $\underline{\mathrm{s} 10980-009-9347-7}$

Verburg, P. H., and K. P. Overmars. 2009. Combining top-down and bottom-up dynamics in land use modeling: exploring the future of abandoned farmlands in Europe with the Dyna-CLUE model. Landscape Ecology 24(9):1167. https://doi.org/10.1007/ $\underline{\text { s10980-009-9355-7 }}$

Walker, J. M., R. Gardner, and E. Ostrom. 1990. Rent dissipation in a limited-access common-pool resource: experimental evidence. Journal of Environmental Economics and Management 19(3):203-211. https://doi.org/10.1016/0095-0696(90)90069-B 
Appendix 1

Table 1: The effects on appropriation and provision levels on stock productivity

\begin{tabular}{cccc}
\hline \multicolumn{2}{c}{ Stage-1 appropriation } & \multicolumn{2}{c}{ Stage-2 provision } \\
\hline Tokens & Productivity 1 & Tokens & Productivity 2 \\
\hline \hline $200(100 \%)$ & 1.1 & 80 & 2.5 \\
$180(90 \%)$ & 1.3 & 72 & 2.25 \\
$160(80 \%)$ & 1.5 & 64 & 2 \\
$140(70 \%)$ & 1.3 & 56 & 1.75 \\
$120(60 \%)$ & 1.1 & 48 & 1.5 \\
$100(50 \%)$ & 0.9 & 40 & 1.25 \\
$80(40 \%)$ & 0.7 & 32 & 1 \\
$60(30 \%)$ & 0.5 & 24 & 0.75 \\
$40(20 \%)$ & 0.3 & 16 & 0.5 \\
$20(10 \%)$ & 0.1 & 8 & 0.25 \\
$0(0 \%)$ & 0 & 0 & 0 \\
\hline
\end{tabular}




\section{Appendix 2: Instructions}

\section{Intro}

Welcome, and thank you for participating!

You are taking part in a study on decision-making, where your own and others' decisions affect your own and others' payouts. The study consists of two rounds of two decisions.

For each of the two rounds, you will be endowed with 10 tokens (a token is worth 0.10 USD). Depending on how well you and your group members invest these tokens, you can more than triple your tokens, but you may also lose some of your tokens.

Before the game starts, you will receive detailed instructions about the decision-making context, followed by a quiz to control for your understanding of the instructions. Correct answer in the quiz will earn you 0.10 USD each. After the game, you will be presented a brief survey about yourself. Completion will be rewarded with an additional 0.50 USD.

Overall, we estimate that it will take you ca. 10-15 minutes to participate, and that average earnings will be around 3.50 USD. You will be paid individually and privately within 48 hours through MTurk.

Next, you will receive detailed instructions about the decision-making tasks. Please read these instructions very carefully as your payout is dependent on your understanding of the situation and on your own and others' decisions.

-Page Skip-

\section{Detailed Instructions (1)}

The decisions you have to make is to invest your token endowments. Remember that 1 token is worth 0.1 USD. Your total earnings will also be calculated in tokens and, at the end of the study, converted to USD (10:1) and paid out to you within a week.

As mentioned previously, the study consist of two rounds. After completing the first round, you will receive a new token endowment and take the same kinds of decisions again under slightly different conditions, for which you will receive new instructions. Each round consists of two stages (two decisions):

\section{Stage 1: an allocation decision}

\section{Stage 2: a contribution decision}

-Page Skip-

\section{Stage 1: allocation decision}

You are endowed with 10 tokens and randomly placed in a group with 19 other subjects recruited from Amazon's Mechanical Turk. Your and the others' identities will remain entirely anonymous. All participants in your group will face the same decision situation as you.

Your task in the first stage is how many of your 10 tokens you want to allocate to a group account. The remainder is automatically assigned to a private account. Your total earnings from the round include earnings from both your private and your group account.

- Your earnings from allocating tokens to the private account equal one-to-one what you allocated to the private account. Earnings from the private account do not depend on the decisions of others.

- Your earnings from the group account depend on the total number of tokens allocated to this account by you and by the 19 other members of your group. (Exactly how we explain in detail shortly). 


\section{-Page Skip-}

\section{Stage-2: contribution decision}

Your task in stage-2 is to decide on contributing tokens to maintain / improve the productivity of the group account. Each additional token contributed by you and your group members in this stage increases the "productivity" of the group account. That is, it will increase the earnings for tokens allocated to the group account in Stage 1 for you and your group members, but the contribution you make here is subtracted from your total earnings at the end of the round. Everybody will be suggested to contribute a "fair share" of $20 \%$ of the tokens you allocated to the group account in Stage 1. However, that contribution is voluntary, and may range from 0 to 4 tokens.

Therefore, your total earnings from a round of decisions equals

\section{Earnings from the individual account}

\section{+ Earnings from the Group account}

\section{- Contributions made to the group account}

Next, we explain in detail how the groups' Stage-1 and Stage-2 decisions affect the earnings from tokens allocated to the group account.

-Page Skip-

The effect of Stage-1 decision on the productivity of the group account

Both Stage-1 and Stage-2 decisions affect the earnings from tokens allocated to the group account.

Regarding Stage-1 allocations; the productivity of group account is best when tokens allocated in Stage 1 meet the accounts "capacity". The so-called capacity of the group account is 160 tokens (or $80 \%$ of the group endowment). At this level the group account has a productivity of 1.5 . That is, it returns 1.5 tokens per token allocated. However, for group allocations below and above the capacity, productivity reduces by 0.2 points per $10 \%$ deviation, as detailed in the table below.

\begin{tabular}{|r|r|}
\hline \multicolumn{2}{|c|}{ Stage-1 allocation } \\
\hline Tokens & Productivity 1 \\
\hline $200(100 \%)$ & 1.1 \\
\hline $180(90 \%)$ & 1.3 \\
\hline $160(80 \%)$ & 1.5 \\
\hline $140(70 \%)$ & 1.3 \\
\hline $120(60 \%)$ & 1.1 \\
\hline $100(50 \%)$ & 0.9 \\
\hline $80(40 \%)$ & 0.7 \\
\hline $60(30 \%)$ & 0.5 \\
\hline $40(20 \%)$ & 0.3 \\
\hline $20(10 \%)$ & 0.1 \\
\hline $0(0 \%)$ & 0 \\
\hline
\end{tabular}

-Page Skip- 
Productivity of the group account is further dependent on Stage-2 contributions. That is each additional token contributed in Stage 2 improves the productivity of the collective account. A total of 32 tokens are needed to maintain the accounts productivity. This equals the suggested $20 \%$-contributions when Stage- 1 allocations match the accounts capacity. If contributions fall below/exceed the required level of 32 tokens, productivity of the account drops/increases by 0.25 points per 8 tokens.

\begin{tabular}{|r|r|}
\hline \multicolumn{2}{|c|}{ Stage-2 contribution } \\
\hline Tokens & Productivity 2 \\
\hline 80 & 2.5 \\
\hline 72 & 2.25 \\
\hline 64 & 2 \\
\hline 56 & 1.75 \\
\hline 48 & 1.5 \\
\hline 40 & 1.25 \\
\hline 32 & 1 \\
\hline 24 & 0.75 \\
\hline 16 & 0.5 \\
\hline 8 & 0.25 \\
\hline 0 & 0 \\
\hline
\end{tabular}

Finally, the earnings from group account are calculated by multiplying the resulting productivities from Stage1 and Stage-2 decisions (Productivity 1 x Productivity 2). Given this setting, the productivity of the group account will take a value between 0 and 3.75. That is, he tokens you allocated to group account you may get no return or almost 4 times the tokens that you allocated in the group account.

For example, if total group allocations in Stage 1 match the capacity of $80 \%$ and everybody contributes the suggested $20 \%$ of the tokens he earlier allocated to the group account, it will result in Stage- 2 contributions of 32 tokens. In this case, the earnings from a token invested in the group account will be 1.5 token, as the total productivity calculates as 1.5 (Productivity 1$) \times 1$ (Productivity 2 ).

--Page skip- 


\section{In the following we provide 3 examples for illustrative purposes.}

Example 1. Assume that you have allocated 5 tokens to the Group account. Suppose that each of the other group members (remember you are in a group of 20) have also allocated 5 tokens to the Group account in Stage 1. Further assume that you have contributed 1 token for the productivity of the group account in Stage 2 , and everybody else also contributed 1 token. Then, the total of 100 tokens allocated in stage-1, together with 20 tokens contributed in Stage 2 results in the productivity of the group account of $0.5625(0.9 \times 0.625)$. In this scenario your earnings for this round will be 6.8 tokens $(5$ tokens from the individual account +2.8 tokens $(5$ tokens $* 0.5625$ ) from the group account -1 token contributed in stage 2 ).

Example 2. Assume that you have allocated 8 tokens to the Group account. Suppose that each of the other group members (remember you are in a group of 20) have also allocated 8 tokens to the Group account in Stage 1. Further assume that you have contributed 2 tokens for the productivity of the group account in Stage 2 , and everybody else also contributed 2 tokens. Then, the total of 160 tokens allocated in stage- 1 , together with 40 tokens contributed in Stage 2 results in the productivity of the group account of 1.875 (1.5 x 1.25). In this scenario your earnings for this round will be 15 tokens ( 2 tokens from the individual account +15 tokens $(8$ tokens $* 1.875$ ) from the group account -2 tokens contributed in Stage 2).

Example 3. Assume that you have allocated 10 tokens to the Group account. Suppose that each of the other group members (remember you are in a group of 20) have also allocated 10 tokens to the Group account in Stage 1. Further assume that you have contributed 4 tokens for the productivity of the group account in Stage 2, and everybody else also contributed 4 tokens. Then, the total of 200 tokens allocated in stage-1, together with 80 tokens contributed in Stage 2 results in the productivity of the group account of 2.75 (1.1 x 2.5). In this scenario your earnings for this round will be 21 tokens $(0$ tokens from the individual account +25 tokens $(10$ tokens $* 2.5)$ from the group account -4 tokens contributed in stage 2$)$. 


\section{Overview Setting "Baseline"}

Group size $=20$

Endowment $=10$

Productivity of private account $=1$

Initial productivity of group account $=1.5$

Capacity of group account $=160$

Expected contributions $=20 \%$ of your investment into the group account

\section{Control questions}

$\mathrm{C} 1$ : Given this setting, what average individual investments into to group account would be best for iits productivity?
○ 0 tokens
- 5 tokens
- 8 tokens
- 10 tokens

$\mathrm{C} 2$ : For someone investing 5 tokens into the group account, what would you say is a "fair" contribution to group account?
○ 0 token
○ $\quad 0.4$ tokens
○ 0.5 tokens
○ 1 token
○ 2 tokens

C3: If all group members allocate $80 \%$ of their endowment to the collective account, and on average exceeded their expected contributions, how much would the group account return per token invested?
- More than 1.5 tokens
- 1.5 token
- 1 token
○ 0.5 token

--skip-- 


\section{Instruction $\mathbf{T} 2$}

In this round, you are now in a smaller group of 10 individuals. The capacity of the collective account is reduced to 80 tokens, and now requires only 16 contributed tokens to maintain its productivity. All other factors remain equal.

\section{Overview}

Group size $=10$

Endowment $=10$

Productivity of private account $=1$

Initial productivity of group account $=1.5$

Capacity of collective account $=80$

Expected contributions $=20 \%$ of your investment into the group account

Instruction $\mathbf{T 3}$ (in this treatment a token is equal to 5 Cents)

For this round, you are now in a smaller group of 10 individuals, but all of you are now endowed with 20 tokens. All other factors remain equal.

\section{Overview}

Group size $=10$

Endowment $=20$

Productivity of private account $=1$

Initial productivity of group account $=1.5$

Capacity of collective account $=160$

Expected contributions $=20 \%$ of your investment into the group account

Instruction 4 (in this treatment a token is equal to 5 Cents)

For this round, you are now endowed with 20 tokens and the capacity of group account is 320 tokens, and it now requires 64 contributed tokens to maintain its productivity. All other factors remain equal

\section{Overview}

Group size $=20$

Endowment $=20$

Productivity of private account $=1$

Initial productivity of group account $=1.5$

Capacity of collective account $=320$

Expected contributions $=20 \%$ of your investment into the group account 


\section{Instruction 5}

For this round, the initial productivity of the group account increases up to the factor 2 . All other factors remain equal

\section{Overview}

Group size $=20$

Endowment $=10$

Productivity of private account $=1$

Initial productivity of group account $=2$

Capacity of collective account $=1600$

Expected contributions $=20 \%$ of your investment into the group account

\section{Instruction 6}

For this round, you are now expected to contribute $40 \%$ of the tokens invested into the group account. All other factors remain equal.

\section{Overview}

Group size $=20$

Endowment $=10$

Productivity of private account $=1$

Initial productivity of group account $=1.5$

Capacity of collective account $=800$

Expected contributions $=40 \%$ of your investment into the group account

\section{Instruction 7}

This round introduces a rewarding mechanism for those contributing more than their expected share. If you exceed the suggestion, you have a 50\% chance of being picked for reward. In that case, we will increase your return from tokens invested into the group account by the same factor you have exceeded your expected contributions. All other factors remain equal.

For example, if you allocate 5 tokens to the group fund in stage-1, and then decide to contribute 1.5 tokens $(30 \%)$, instead of the suggested one token $(20 \%)$, you "over-contribute" by the factor 1.5 . In that case, you have a $50 \%$ chance of being randomly selected for the rewarded. If selected, the tokens you have allocated to the group account will not just return with resulting productivity - let's say that would be 1.2 - but instead, the resulting productivity is multiplied by the factor you have overcontributed $(1.2 * 1.5)$. This will leave you with a return of 1.8 for each of the five tokens invested in the group account.

\section{Overview}

Group size $=20$

Endowment $=10$

Productivity of private account $=1$

Initial productivity of group account $=1.5$ 
Capacity of collective account $=800$

Expected contributions $=20 \%$ of your investment into the group account

\section{Instruction 8}

This round introduces a sanctioning mechanism for those contributing more than their expected share. If you contribute less than your expected contribution, you have a $50 \%$ chance of being detected and sanctioned. In that case, we will decrease your return from tokens invested in the group account by the factor you felt below your expected contributions. All other factors remain equal.

For example, if you allocate 5 tokens to the group fund in stage- 1 , and then decide to contribute 0.5 tokens $(10 \%)$, instead of the suggested one token $(20 \%)$, you (under-)contribute with a factor 0.5 . In that case, you have a $50 \%$ chance of being randomly detected and sanctioned. If selected, the tokens you have allocated to the group account will not return with resulting productivity - let's say that would be 1.2 - but instead, the resulting productivity is multiplied by the factor you have (under-)contribution factor $(1.2 * 0.5)$. This will leave you with a return of 1.8 for each of the five tokens invested in the group account.

\section{Overview}

Group size $=20$

Endowment $=10$

Productivity of private account $=1$

Initial productivity of group account $=1.5$

Capacity of collective account $=800$

Expected contributions $=20 \%$ of your investment into the group account 


\section{Appendix 3: Personal Survey}

\begin{tabular}{|c|c|c|c|c|}
\hline No & Demo_Variable & Question & & Answer options \\
\hline \multirow[t]{3}{*}{1} & Gender & What is your gender? & 1 & Female \\
\hline & & & 2 & Male \\
\hline & & & & Intersex \\
\hline \multirow[t]{7}{*}{2} & Age & What is your age? & & \\
\hline & & & 1 & $15-24$ \\
\hline & & & 2 & $25-34$ \\
\hline & & & 3 & $35-44$ \\
\hline & & & 4 & $45-54$ \\
\hline & & & 5 & $55-64$ \\
\hline & & & 6 & years \\
\hline \multirow[t]{5}{*}{3} & Marital Status & What is your marital status? & 1 & \multirow{5}{*}{$\begin{array}{l}\text { Single, never married } \\
\text { Married or domestic partnership } \\
\text { Widowed } \\
\text { Divorced } \\
\text { Separated }\end{array}$} \\
\hline & & & 2 & \\
\hline & & & 3 & \\
\hline & & & 4 & \\
\hline & & & 5 & \\
\hline \multirow[t]{12}{*}{4} & Education & $\begin{array}{l}\text { What is the highest degree or level of education you have } \\
\text { completed? }\end{array}$ & & \\
\hline & & & 1 & No schooling completed \\
\hline & & & 2 & Some high school, no diploma \\
\hline & & & 3 & $\begin{array}{l}\text { High school graduate, diploma or the equivalent } \\
\text { (for example: GED) }\end{array}$ \\
\hline & & & 4 & Some college, no degree \\
\hline & & & 5 & Trade/technical/vocational training \\
\hline & & & 6 & Associate degree \\
\hline & & & 7 & Bachelor's degree \\
\hline & & & 8 & $\begin{array}{l}\text { Master's degree } \\
\text { Professional degree }\end{array}$ \\
\hline & & & 9 & Professional degree \\
\hline & & & 10 & Doctorate degree \\
\hline & & & 11 & Other \\
\hline
\end{tabular}

4a Education How many schooling years including higher education

have you completed?

$\begin{array}{ll}0-5 & \text { years } \\ 6-10 & \text { years } \\ 11-15 & \text { years }\end{array}$


Less than $25^{\prime} 000$

25'000-50'000

$500^{\prime} 000-75^{\prime} 000$

75'000-100'000

Over 100 '000

$6 \quad$ Employment status $\quad$ What is your current employment status?

Employed part time (less than 30 hours a week)

Employed full time

Self employed

Unemployed

Retired

Not employed - unable to work

Student (and working less than 20 hours a week)

Other

\begin{tabular}{lll}
\hline 7 & Responsibility $\quad$ What is the degree of responsibility in your job?
\end{tabular}

Top managment / Senior executive

Upper Middle (Departmental Executives, Factory Managers, Senior

Professional Staff)

Middle (Office Managers, Professional Staff, Mid-Level Administrators)

First Level (Forepersons, Supervisors)

Waged Staff (Machine Operators, Clerical/Secretarial and Support Staff,

Technicians)

\begin{tabular}{|c|c|c|c|c|c|c|c|}
\hline 8 & Attitudes & To what extent do you agree with the following statements? & $\begin{array}{l}\text { fully } \\
\text { agree }\end{array}$ & $\begin{array}{l}\text { rather } \\
\text { agree }\end{array}$ & not sure & $\begin{array}{l}\text { rather } \\
\text { disagree }\end{array}$ & $\begin{array}{l}\text { totally } \\
\text { disagree }\end{array}$ \\
\hline a & & Everybody should be responsible for his own economic success & 1 & 2 & 3 & 4 & 5 \\
\hline b & & Economic success is important to me & 1 & 2 & 3 & 4 & 5 \\
\hline c & & It is important to give back to the community & 1 & 2 & 3 & 4 & 5 \\
\hline $\mathrm{d}$ & & $\begin{array}{l}\text { Sometimes it is important to act in the interest of the group, rather than } \\
\text { in one's own interest }\end{array}$ & 1 & 2 & 3 & 4 & 5 \\
\hline
\end{tabular}

